\title{
ECONOMIC DEVELOPMENT AND THE QUALITY OF LIFE OF CHILDREN*
}

\author{
MARCELO DELAJARA
}

Universidad Empresarial Siglo 21 ${ }^{\text {a }}$

\begin{abstract}
RESUMEN
Los estudios históricos muestran que el crecimiento secular de la estatura media de los niños europeos occidentales comenzó en 1850 y fue precedido por cien años de declive y estancamiento. Conjeturamos que la caída inicial en las estaturas está relacionada con la transición demográfica y mostramos que una extensión del modelo neoclásico de crecimiento económico puede explicar el fenómeno. Verificamos que las predicciones del modelo se cumplen en el presente para un corte transversal de países y encontramos que, en países con bajo ingreso por habitante, la estatura media de los niños está negativamente asociada con el ingreso per capita y con la fecundidad. Como ejercicio final, nos preguntamos si estas estimaciones explican el cambio en la estatura media observado en el último siglo y medio.
\end{abstract}

Palabras clave: crecimiento económico, fecundidad, calidad de vida, estatura infantil, análisis de sección cruzada

\footnotetext{
* I thank Jörg Baten, Rosa María Fernández, Joan Ribas-Tur, Raymond Robertson, Xavier Sala i Martín, Danilo Guaitoli, Pedro Mira, Guillem López, Gary S. Becker, John Komlos, Michelangelo van Meerten, and seminar participants at Universitat Pompeu Fabra; Universidad de San Andrés; CEMA; the 2002 Conference on Economics and Human Biology held in Tübingen, Germany; the 2001 World Congress of the International Health Economics Association in York, England; the 1999 Latin American Meeting of the Econometric Society in Cancún, México; the 1999 World Congress of the International Economics Association in Buenos Aires, Argentina; the 1998 Meeting of the European Society for Population Economics in Amsterdam, The Netherlands, for very helpful comments. Financial aid from The Spanish Ministry of Education and Culture through an FPI Scholarship at Universitat Pompeu Fabra is gratefully acknowledged. Remaining mistakes and shortcomings are my responsibility.

a Ituzaingó 484, X5000IJJ Córdoba, Argentina. mdelajara@uesiglo21.edu.ar
} 


\begin{abstract}
Historical studies show that the average height of Western European children began its secular growth in 1850 only after a period of decline and stagnation which had started around 1750 . We argue that the initial downturn in heights is related to the demographic transition, and show that an extension of the neoclassical model of economic growth can explain the observed phenomena. We test whether the predictions of the model hold for a cross-section of contemporary countries, and we find that stature is indeed negatively associated with income per capita and fertility for countries with an income per capita below a given threshold. As a final exercise, we ask whether these cross-country estimates explain the improvement in children's height observed in the last hundred and fifty years.
\end{abstract}

Keywords: economic growth, fertility, quality of life, children's stature, crosscountry analysis

JEL Classification: O11, J13, I12, I31, N3

\title{
1. INTRODUCTION
}

The literature on the relation between the quality of life of children and income per capita has mainly concentrated on the evolution of infant mortality; for instance, Pritchett and Summers (1996) show that infant mortality falls with income per capita.

These findings indicate that survival chances increase with income per capita growth but do not tell us much, however, about the quality of life of surviving children. According to the findings of economic historians at least one measure of the quality of life of children, their biological standard of living -characterized by their height-for-age-, seems to have displayed a nonlinear association with income per capita growth.

The historical evolution of average height in Europe is characterized by three stylized facts: first, children and adolescents have experienced a sustained upward shift in their height-for-age profile since about 1850; second, average height first declined and then stagnated during the initial stages of economic development, between 1750 and 1850; third, a convergence in children's height for age is observed over regions, social classes and occupations since then ${ }^{1}$.

${ }^{1}$ Some important contributions to this «Anthropometric History» are Fogel (1994); Floud et al. (1990), (1993a) and (1993b); Harris (1994); Komlos (1989), (1993a), and (1993b); Komlos and Coclanis (1997); Sandberg and Steckel (1988) and (1997); Steckel (1995); Weir (1993). In particular for Spain, see Coll and Quiroga (1994), Martínez Carrión (1994) and Quiroga (2001). 
This nonlinear relation does not seem to be an exception in the literature on income and the quality of life. Easterly (1999) shows that several quality of life indicators -other than children's stature-are positively related to income per capita in the long-run but not in the short-run, which might be suggesting that these quality of life indicators improve only after a certain level of income per capita has been reached.

To analyze the relation between income per capita and the quality of life of children we therefore need to focus on indicators that capture living conditions during childhood more accurately than infant mortality. The average height of children of a given age in a given economy is a good indicator of their standard of living ${ }^{2}$. Because of its «ex-post» nature stature has an advantage over infant mortality as an indicator of the quality of life during childhood. Stature is available for a wide range of periods and countries, and it was one of the first indicators for the standard of living to be studied by social scientist in the nineteenth century ${ }^{3}$.

The main working hypothesis of this paper is that a theory of the evolution of the quality of life of children should be able to explain the historical evolution of children's height-for-age.

Many authors have tried to give a coherent explanation to the evolution of average heights. While there seems to be a consensus in considering long-run income growth as the main cause behind the historical increases in children's average stature, there is considerable dispute among researchers regarding the forces behind the observed initial temporary decline in heights.

It is considered an «early-industrial-growth puzzle» that average height fell during those initial periods of income per capita growth ${ }^{4}$. Some authors claim that larger income inequality, declines in food production and consumption per capita, increases in food prices relative to manufactures, and a deterioration of the disease environment -all of them allegedly observed during industrial revolution timesmight have been the cause of the decline in height ${ }^{5}$.

An alternative explanation for the evolution of stature is given in Weir (1993) and Schneider (1996), who stress the effects of parental expenditures on children's nutritional status, and the role of fertility in those parental decisions. Weir (1993, p. 265) states that: «In the nineteenth century, calorie intake rose quickly relative to GNP, whereas heights improved slowly. In the twentieth century, GNP growth

\footnotetext{
${ }^{2}$ Eveleth and Tanner (1976) and (1990), is the main reference here.

${ }^{3}$ Although stature was considered to be linked to wealth and well-being from the very beginning, discussions on the determinants of stature revolved around the "nature versus nurture» dichotomy until well into the twentieth century. See van Meerten (1990), for a more detailed account of the supporters and challengers on each side of the nature versus nurture debate.

${ }^{4}$ Komlos (1998).

${ }^{5}$ See, for example, Frank and Mustard (1992); Komlos (1996) and (1998); Komlos and Coclanis (1997) and Steckel (1995).
} 
accelerated whereas calories remained stable and heights grew rapidly». According to the same author (Ibidem): «[increases in] GNP did not translate into mean calorie intake, and mean calorie intake did not translate directly into improved height» until fertility started to fall. In a panel of European countries since 1850 they indeed find that income per capita has a positive impact on average stature but that fertility has a negative one. Weir (1993) thus provides a better explanation than previous authors for the long-run trend in mean height but leaves unexplained, again, the initial downturn in heights.

The approach followed in this paper -to explain the historical evolution of children's height-for-age- is essentially that of Weir (1993) and Schneider (1996) but we believe that a complete story of children's height changes must provide a coherent and unified explanation for both the long-run trend and the so-called «growth puzzle», i.e. the temporary downturn in children's stature observed in the initial stages of economic development.

The need for a unified approach is motivated by the evidence discussed in the rest of this section. This evidence shows that fertility is likely to have been involved in the main episodes of height declines in England, Sweden and the USA.

Komlos (1993a) estimates that adolescents' average height fell in England during the second half of the eighteenth century, stagnated in the first decades of the nineteenth century and started their long-run increase after the 1850s. These movements in heights were contemporaneous to the demographic transition. According to Wrigley and Schofield (1989) cohort fertility rate increased until the late 1790s, it decreased thereafter, first slowly and after 1850 very fast. If we allow for actual fertility to peak, say, 30 years after cohort fertility, then we see that fertility changes have the opposite sign of the contemporaneous changes in heights during the whole period.

Swedish height data in Sandberg and Steckel (1988 and 1997) along with Swedish cohort fertility data in Eckstein, Mira and Wolfin (1997) reveal that fluctuations in heights coincided with fluctuations in fertility. The turning points in the height series seem to have followed the pattern of the turning points of the fertility series. Between the 1730s and the 1770s fertility was low, while between the 1770s and the 1810 s it was high. Average stature, on the other hand, grew from about 1790 until the 1820 s and then fell between the 1830s and 1850s. If we take the midpoint of each fertility regime as a reference, and assume that actual fertility peaks about 30 years later than cohort fertility, then men born between 1780 and 1820 should have achieved a higher stature than men born between 1820 and 1850, since the former grew up in a period of low fertility: this is precisely what the data indicates. The secular increase in heights started in Sweden, as in England, after 1850 coinciding with the definitive decline in fertility there.

The episodes of height decline in the United States seem to display a similar pattern. Height data from the State of Georgia in the South of the US indicate a decline in the physical stature of the white people beginning in the second half of 
the $1830 s^{6}$. The evolution of heights seems to be correlated with changes in some demographic indicators. For the South Atlantic region as a whole, and for Georgia in particular, the dependency ratio -the percentage of children 14-year-old and younger over total population-jumps from a mean of $30 \%$ in mid 1830 s to about $45 \%$ in 1860 ; then it starts to decrease again; but it takes about a hundred years to go back to the level of the $1830 \mathrm{~s}^{7}$. There is evidence of height decline in other regions for the same period, and the behavior of fertility is also similar. The percentage of the 5-to-14 year-old over total population increases about $10 \%$ in the Northeast, and almost $15 \%$ in the North Central regions.

All these pieces of evidence seem to suggest that not only income per capita, but also fertility, was increasing during height decline episodes. Therefore any account of these episodes must involve both income and fertility dynamics, and their relationship with children's well-being.

In Section 2 we introduce a neoclassical model of economic growth with endogenous fertility in which we distinguish the standard of living of children from that of their parents. We solve the model for a set of standard parameter values and study the dynamics of fertility, children's standard of living, and capital accumulation.The model predicts a nonlinear U-shaped relation between the quality of life of children and income per capita.

The model shows why the increase in fertility associated with income growth in underdeveloped economies leads to a deterioration in the living conditions of children there; and why for developed economies the declining pattern of fertility frees resources to improve the standard of living of children. In short, the model introduced here explains why standard of living during childhood does not improve steadily with income per capita, as the historical height studies show.

Following the model, and given that the industrial revolution and the demographic transition have proceeded at different paces in different countries, the historically observed pattern of height changes should also be observable in a cross-section of countries today ${ }^{8}$. In Section 3 we test whether the predictions of the model hold in a cross-section of contemporary countries. We use average stature at age 10 as the indicator for the quality of life of children in each country.We find that stature is indeed negatively associated with income per capita at low income per capita levels, but positively associated after a threshold value of income per capita is reached.

Two previous attempts to estimate the relation between income and stature in a cross-section of countries are Steckel (1983) and Frongillo and Hanson (1995). Although our estimations and theirs are based on the same height-data source, their results differ substantially from ours.

\footnotetext{
${ }^{6}$ Komlos (1996) and Komlos and Coclanis (1997).

${ }^{7}$ US Department of Commerce (1989).

${ }^{8}$ Lucas (2002).
} 
While Steckel finds that average heights are very sensitive to income per capita, with a large positive elasticity, Frongillo and Hanson find no significant relation between income and heights. We find an income elasticity of children's average height which is positive or negative depending on the level of income per capita of the country; and, when positive, it is always much lower than the one found in Steckel (1983).

Two main shortcomings of those papers are that they lack a formal framework motivating the regression equations estimated, and that height data of minorities are pooled together with country-wide measures of income and other variables. The lack of a model to motivate the estimation leads these authors to leave important variables such as fertility and education out of the model. The use of data on height which are not representative of a country's average, for instance the average height of minority groups, may bias the estimates. In this paper we limit the number of observations to those representative of the country's average height.

In section 4, we summarize the main results and discuss how these cross-country estimates could be used to explain the evolution of average height over time. We show that most of the change in height can be explained by the model.

\section{THE MODEL}

In this section we extend the neoclassical model of economic growth with endogenous fertility to study the evolution of income, fertility, and the standard of living of children.

The standard of living of children - or quality of life of children- is assumed to be a commodity produced at home with family resources. The relation between the number of children households choose to have and their standard of living -basically a version of Gary S. Becker (1976) quantity-quality trade-off-, is a crucial element of this model. Increasing the quality of life of each new born will be costly for the family and therefore will affect the family's demand for children. The reverse will be also true; increasing fertility will deviate resources from children's living conditions to the production of more children.

We start by showing how to introduce the standard of living of children in the preferences and budget constraints of the representative household of the model.

\subsection{Preferences and Technology}

Our benchmark model is the Becker and Barro (1988) fertility model in continuous time, as developed by Barro and Sala-i-Martin (1995) ${ }^{9}$. In this model generations are

${ }^{9}$ This model belongs to the family of models that explain the demographic transition -and the transition from Malthusian stagnation to modern economic growth- as the result 
linked through altruism. The representative parent in generation $i$ is assumed to care for family consumption $C_{i}$, the number of children $n_{i}$, and for the level of adult utility achieved by the children $U_{i+1}$. This future utility level is discounted by a factor, $\mathrm{Y}\left(n_{i}\right)$, which is inversely related to $n_{i}$. The function $u\left(C_{i}, n_{i}\right)$ represents the utility an adult of generation $i$ obtains from consumption and the number of children, and $Y\left(n_{i}\right) n_{i} U_{i+1}$ is the discounted utility achieved by the next generation; then total utility achieved by an adult of generation $i$ is given by $U_{i}=u\left(C_{i}, n_{i}\right)+Y\left(n_{i}\right) n_{i} U_{i+1}$.

This formulation does not distinguish the goods allocated to children during their childhood from the consumption of their parents. It is here where we depart from the original model.We want to analyze the evolution of the standard of living of children, so we reinterpret $C_{i}$ as an index of family «consumption» which is determined by adult consumption $c_{i}$ and by a home-produced commodity $q_{i}$, children's standard of living. Let's assume here that the index $C_{i}$ has the following constant-share form $C_{i}=c_{i}^{\sigma} q_{i}^{1-\sigma}$, with $0<\sigma<1$, and where $\sigma$ is the share of adult consumption on family «Consumption» ${ }^{10}$.

It would be natural to link commodity $q_{i}$ to the mortality rate prevailing among children of generation $i$. We do not deal explicitly with infant mortality, however. Rather, we think of $n$ as the net fertility rate. A consequence of this assumption is that children are costly as long as they survive.

Each child costs an amount $\eta$. In our model, this cost $\eta$ has two components; a fixed cost $\Lambda$ which represents the cost of bearing a surviving child, and a variable cost which increases with improvements in the standard of living of surviving

of changes in the relative cost of quantity to quality of children. Close relatives are Becker, Murphy, and Tamura (1990) and Lucas (2002, chapter 5), although the emphasis and objectives vary greatly from those models to ours. Other important contributions are Galor and Weil (1996), and Galor and Weil (2000), models where the dynamics of the relative cost of quantity to quality are explicitly modeled; and Galor and Moav (2002), where the form of parental preferences for quality and quantity is endogenously determined as a natural selection process.

${ }^{10}$ It is important to discuss here three issues related to the form we have assumed for parental preferences. First, it might seem odd that parents care about their children in two different ways -they care about their standard of living when young, and their utility when old-; but what we are actually assuming here is that parents derive utility from their children's quality in two ways: indirectly through the discounted utility of the next generation, and directly through the commodity $q$. Higher quality children are just more expensive children, even if the higher expenditure does not necessarily increase their future income (Becker, 1976). See also Notes 13 and 15 for the implications of this assumption. Second, the commodity $q$ is assumed to be produced not only with the child's food consumption, but also with parental time in child care, and with the services derived from sanitary infrastructure and medical services; therefore, the dynamics of $q$, both historically and in the model, might be unrelated to the actual historical pattern of children's food consumption. Third, we assume an altruistic framework, but there are alternative non-altruistic formulations in the literature for parental preferences; see for example Cigno (1991). 
children, $q$. We have already mentioned that $q$ is produced at home ${ }^{11}$. We assume that the home production technology is such that the production of one unit of $q$ requires $\lambda$ units of the numeraire good produced in the economy. Then, the birth and rearing cost of each surviving child is $\eta=\Lambda+\lambda q$.

Given our interpretation of $n$, and if $N$ is family size, then the change in the size of the family per unit of time is given by the following law of population growth

$$
\dot{N}=n N
$$

Since $n N$ is the number of new members of the family per unit of time, $(\Lambda+\lambda q) n N$ are total expenditures on children.

To derive a utility function consistent with a continuous time growth model, we follow Barro and Sala-i-Martin (1995) and adopt their parameterization of the model ${ }^{12}$. Then, iterating forward on the discrete utility function above we get the dynastic continuous form for the household's utility function

$$
U=\int_{0}^{\infty} e^{-\rho t}\left[\left(\left(N^{\varphi} c^{\sigma} q^{1-\sigma} n^{\phi}\right)^{1-\theta}-1\right) /(1-\theta)\right] d t
$$

The dynastic utility function is the discounted sum of all future instantaneous utilities, which themselves depend on adult consumption, the fertility rate, and standard of living of children at each date. Instantaneous utility is characterized by the standard property of constant inter-temporal elasticity of substitution; where $\theta^{-1}$ is the value of this elasticity.

Due to the parameterization chosen the discount factor has two components: one which depends on fertility and is represented by the term $N^{\varphi}$ in the instantaneous utility function (again see Note 12), and another component which is constant and represented by the traditional discount factor $\rho$, with $0<\rho<1$.

The stock of human and physical capital of the family is given by $K$. The stock of capital, $K$, and the size of the family, $N$, are the state variables of the model. The rate of return to capital is $r$. Each member of the family supplies un-elastically 1 unit of working time and receives a wage $w$ per unit of time. Thus family labor supply coincides with family size, and total family income is given by $w N+r k$.

\footnotetext{
${ }^{11}$ I follow the ideas in Becker (1965) and Lancaster (1991), regarding home production.

${ }^{12}$ We assume a constant elasticity form for the discount factor $\mathrm{Y}\left(n_{i}\right)=\mathrm{Y} n_{i}^{-\varepsilon}$, and for the utility function $\left.u(c, q, n)=\mid\left(c^{\sigma} q^{1-\sigma} n^{\phi}\right)^{1-\theta}-1\right] /(1-\theta)$. We also define $N_{j}$ as the size of the family in generation $j$; set $N_{i}=1, N_{j}=\prod_{k=i}^{j-1} n_{k}$, for $j>i$, and assume $\varphi=(1-\varepsilon) /(1-\theta)>0$.
} 
The wage and the return to capital depend on the capital-labor ratio, $k$. Per capita production is $y=A k^{\alpha}$, where $\alpha$ is the capital share and $A$ is a (constant) technological parameter. Then the equilibrium wage equals the marginal product of labor, i.e. $w=(1-\alpha) A k^{\alpha}$, and the return to capital is its rental price minus the depreciation, i.e. $r=\alpha A k^{\alpha-1}-\delta$, where $\delta$ is capital's depreciation rate ${ }^{13}$. Since there is no technological change, there is only growth in income per capita during the transition to the steady state.

Income is allocated to alternative uses: $\dot{K}$ is family savings in the form of physical and human capital accumulation; $c N$ is family's adult consumption; and $(\Lambda+\lambda q) n N$ is total expenditure on children. The budget constraint, in per capita terms, is then given by

$$
c+(\Lambda+\lambda q) n+\dot{k}=w+(r-n) k
$$

which states that expenditures plus saving must equal income.

\subsection{Solving the Model}

The household's problem is to choose the time paths for control variables $c, q$, and $n$ that maximize (2) subject to (1) and (3). If we assume a particular form for the instantaneous utility function in which $\theta \rightarrow 1$-i.e. the instantaneous utility function converges to the log utility form-, the solution of the model is characterized by the following system of equations:

$$
\dot{k}=A k^{\alpha}-(n+\delta) k-c-(\Lambda+\lambda q) n
$$

and

${ }^{13}$ In this model the level of wages depends on the level of per capita human and physical capital in the economy, and is independent from the standard of living of children. Although there is some evidence linking wages to living conditions during childhood, this evidence is still inconclusive and limited to individuals, not to economy wide measures of income and health. Strauss and Thomas (1998) find a positive association between adult height and wages at individual levels, and Case, Lubotsky and Paxson (2001), provide evidence that this positive association can be attributed to health in childhood. On the other hand, Dasgupta (1993), emphasizes that there is no evidence of an association between income and adult height at the macroeconomic level, and that there is no one-to-one link between child height and final adult height. Therefore, we take a conservative stance and remain within the traditional neoclassical model of production for the purpose of determining wages and rates of return to human and physical capital. 
are two first-order differential equations characterizing capital accumulation and adult consumption growth, respectively; while

and

$$
n=\frac{(\sigma+\phi-1)(c / k)}{\sigma(1+\Lambda / k)-\frac{\varphi}{\rho}(c / k)}
$$

give the level of fertility and children's standard of living for given values of the stock of capital. The law of motion in (2) closes the system.

Notice that equation (7) states that the standard of living of children is negatively related to net fertility, and positively related to adult consumption. The relation between adult consumption and fertility will then be crucial for the evolution of the quality of life of children.

This model cannot be solved analytically. We solve it numerically with the timeelimination method developed by Mulligan and Sala i Martin (1991). A key aspect of the system of equations (4)-to-(7) is that one can use (6) and (7) to substitute for $n$ and $q$ in (4) and (5) and thus obtain an autonomous system of differential equations in $c$ and $k$. The time-elimination algorithm then gives us the policy function of adult consumption $c(k)$ and the time path of capital stock $k(t)$ that solve the autonomous system. To find the policy function of children's quality of life, $q(k)$, and the policy function of fertility, $n(k)$, we substitute $c(k)$ and $k(t)$ back into (7) and (6).

The following parameter values are used in the solution of the model:

$$
\alpha=.68 \quad A=1 \quad \rho=.04 \quad \delta=.05 \quad \varphi=.20 \quad=.20 \quad \sigma=.90 \quad \Lambda=50 \quad \lambda=1
$$

These parameter values were kept as similar as possible to the ones used in previous literature. Parameters A, $\delta, \varphi$, , and $\Lambda$ have the same values as in Barro and Sala i Martin (1995), while $\alpha$ and $\rho$ have had their values changed from 0.75 to 0.68 , and from 0.02 to 0.04 , respectively. A discount rate of 0.04 is well within the values usually found in the literature, while the value for $\alpha$ is still consistent with our broad interpretation of capital, representing the sum of both human and physical capital in the model. Two new parameters are $\lambda$ and $\sigma$. The parameter $\lambda$ has been set equal to 1 under the assumption that the commodity $q$ is measured in the same units as adult consumption; while $\sigma$ was set equal to 0.9 so that $1-\sigma=0.1$, which is the share of expenditures on children on total personal consumption in the USA ${ }^{14}$.

${ }^{14}$ From Haveman and Wolfe (1995), and the US National Income and Product Accounts we estimate that total parental expenditures on children -excluding government expenditures on children, housing and transportation- are about $10 \%$ of the US Real Personal Consumption Expenditures, and as a consequence we set $\sigma=0.9$ in the simulation of the model. 


\subsection{The Policy Functions}

Graphs 1 and 2 show graphs of the policy functions that result from the numerical solution of the model. A policy function gives the optimal value of a control variable -fertility, adult consumption, or quality of life of children-for each value of the state variable -stock of physical and human capital-, in per capita terms. Graph 2 also shows the optimal time path of capital accumulation.

The policy functions for fertility, $n(k)$, and the standard of living of children, $q(k)$, are shown in Graph 1. Under the parameterization chosen, the model predicts a nonlinear U-shaped relation between the standard of living of children and the stock of capital per head, and by extension a nonlinear relation between standard of living and income per capita -given the neoclassical production technology assumed. The standard of living of children falls with capital accumulation when the stock of capital per capita is low, but both variables are positively associated when the stock of capital is large. It also predicts a demographic transition characterized by a positive association between fertility and capital stock per capita when the country is poor and a negative association as the country gets richer.

GRAPH 1

\section{FERTILITY AND THE QUALITY OF LIFE OF CHILDREN AS FUNCTIONS OF CAPITAL PER HEAD}
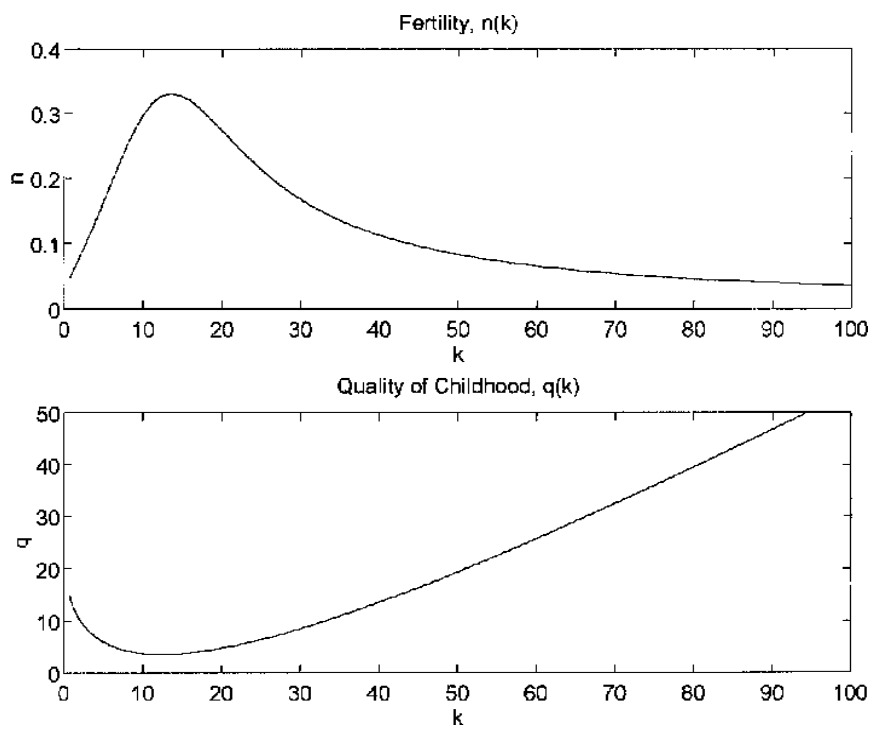
The adult consumption policy, $c(k)$, is shown in Graph 2. Adult consumption grows monotonically with the stock of capital and remains undisturbed by the dynamics of fertility and the standard of living of children.

We can use first order conditions (6) and (7) to interpret the dynamics shown in Graph 1. Equation (6) states that at low levels of capital per capita the fixed cost of each new born is large relative to the stock of capital, and therefore fertility is low; then, as capital is accumulated, the fixed cost of children falls relative to the stock of capital per capita and fertility increases. This initial increase in fertility is larger than the increase in adult consumption and, from (7), we get that the standard of living of children falls. As the stock of capital per head grows, the weight of the fixed cost in the production of children becomes less important and the income effect on fertility vanishes; eventually, fertility starts to decline towards its low steady state value. From equation (7) we then see that the joint effect of declining fertility and increasing adult consumption is to reverse the negative trend in the standard of living of children; the quality of life of children starts to improve with capital accumulation.

\section{GRAPH 2}

\section{CAPITAL ACCUMULATION OVER TIMEAND ADULT CONSUMPTION AS A FUNCTION OF CAPITAL PER HEAD}
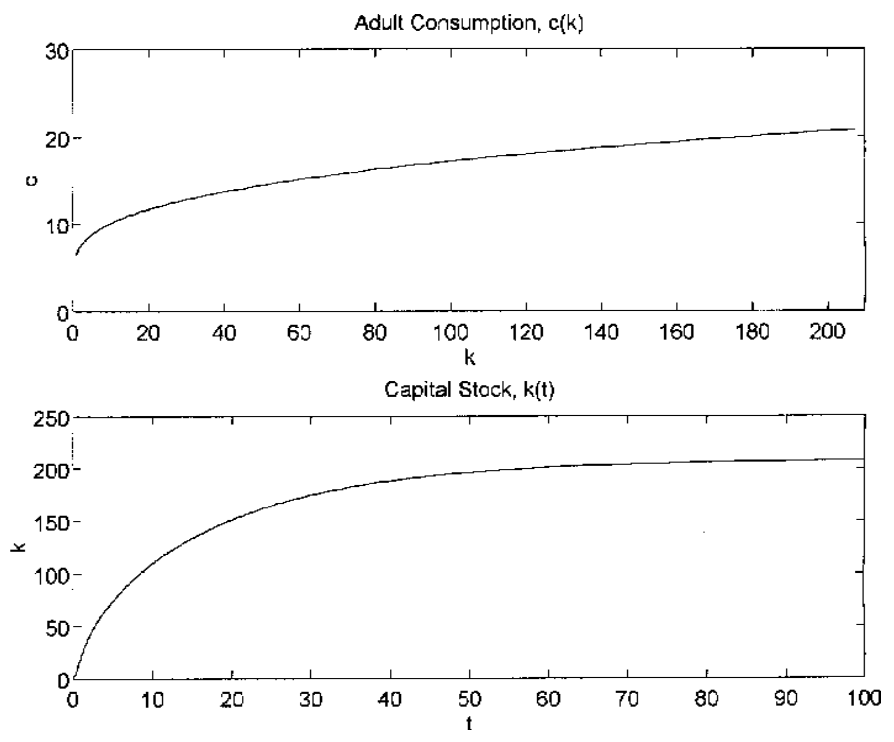
Notice that the stock of capital per head at which standard of living reverses its declining trend is smaller than the stock of capital per head at which fertility peaks. This is so because the positive effect of adult consumption on children's quality of life outweighs the negative effect of fertility as soon as fertility growth begins to slow down.

The solution of the model is completed with the analysis of the behavior of $k$ over time. Graph 2 displays the time path of the stock of human and physical capital. Capital per head grows steadily over time, and converges to the steady state ${ }^{15}$.

Summarizing, the model predicts that living conditions during childhood first decline with economic growth, mainly due to the fast contemporaneous increase in fertility, and that living conditions improve only after fertility growth slows down and fertility starts to fall. In the next section of the paper we show that this pattern of development is supported not only by historical studies of height, but also by the relation between children's stature and income per capita observed across countries today.

\section{CHILDREN’S STATURE AND GDP INACROSS-SECTION OF COUNTRIES}

In this section we estimate the relation between the quality of life of children, fertility, and income per capita in a cross-section of countries. The policy functions derived in the previous section establish that fertility and quality of life can be estimated as reduced-form functions of the stocks of physical and human capital. We use measures of adult educational status and income per capita as proxies for these explanatory variables, and average height-for-age as proxy for the quality of life of children. To be consistent with the model, we use net fertility as the relevant measure of fertility ${ }^{16}$. The estimated relations are then interpreted in the light of the mechanics of the model.

\footnotetext{
${ }^{15}$ As Graph 2 shows, human and physical capital accumulation is affected neither by increasing fertility rates nor by declining living conditions of children. Becker, Murphy and Tamura (1990) introduce a model in which the positive association between fertility and income per capita at low levels of income per capita hampers the accumulation of enough human capital so that very poor countries remain in a poverty trap characterized by low income per capita, high fertility, and low human capital levels. The difference between their model and this one is that they consider all expenditures in children as conducive to larger levels of human capital, while we distinguish investments which improve children's living conditions from expenditures that improve their future income in the form of human and physical capital. This distinction allows us to remain within the neoclassical framework and find a unique equilibrium for the model.

${ }^{16}$ Net fertility is defined as total fertility times (one minus the under five mortality rate).
} 


\subsection{Model Specification}

The theory predicts a nonlinear relation between both fertility and children's height and income per capita. To capture this nonlinearity in the cross-section of countries we estimate a quadratic regression equation using Log(GDP) and Log(GDP) squared as independent variables; Log(GDP) is the logarithm of Gross Domestic Product per capita. From the model we expect the estimated relation between fertility and $\log (\mathrm{GDP})$ to be positive on the linear term and negative on the squared term; while for the average height of children we expect the opposite signs. We also include measures of adult education as independent variables in the regression.

The model predicts that average height and net fertility should be negatively correlated across countries. Graph 3 shows that this negative association is clear in our sample of countries. Both fertility and stature are assumed to be determined by the same set of variables, however, so we estimate the relation between fertility, the height of children, and income per capita in two separate regression equations, one for fertility and one for height. We use log of net fertility and log of height as dependent variables in order to interpret the estimated coefficients as income elasticities.

Steckel (1983 and 1995) suggests that income distribution affects the average height of children, independently of income per capita. We control for income inequality in some of the specifications of the model, using the Gini index as the measure of inequality. Since income inequality is endogenous itself to changes in income per capita and educational attainments, we use instrumental variables (IV) estimation for this specification ${ }^{17}$. To control for the presence of exogenous changes in average stature over time, some specifications of the model include a time trend variable which keeps track of the year height has been measured in each economy ${ }^{18}$. We resort to IV estimation for these specifications as well.

\subsection{The Data}

Data on the average height of children come from Eveleth and Tanner (1976 and 1990) ${ }^{19}$. We work with 10 -year-old boys' height data that are representative of national

\footnotetext{
${ }^{17}$ Barro (2000).

${ }^{18}$ Easterly (1999).

19 They report the average height of children, by sex, age, and ethnicity, for several countries in all continents, as well as the year of height measurement. However, not all the reported heights are representative of national averages. To make sure that representative figures are used, we only make use of the data on heights for those ethnic groups which constitute a majority in a given economy, as well as regional height data representative of national trends.
} 


\section{GRAPH3}

CHILDREN'S AVERAGE STATURE AGAINST NET FERTILITY

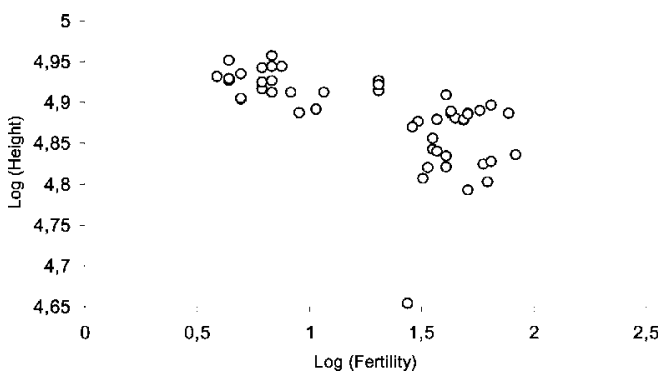

averages $^{20}$. We have observations for 49 countries satisfying these requirements ${ }^{21}$. Date of height measurement differs across countries, so the corresponding values for income and education are those prevailing ten years before in the country. For example, if children have been measured in 1980 in a given country, we use the values for fertility, education, and income per capita prevailing in 1970 in that country.

Table 1 shows summary statistics for the height of children. The tallest children in this sample are the Dutch with an average height of $142,2 \mathrm{~cm}$ at age 10 , while the shortest children in the sample are the Nepalese with $105 \mathrm{~cm}$. This is a range of 37,2 $\mathrm{cm}$ to be explained by GDP per capita and adult education differences across countries ${ }^{22}$.

\footnotetext{
${ }^{20}$ We concentrate on the average height of 10 -year-old boys for two reasons. One reason is that the rate of human growth declines continuously from birth to about the age of 10 in boys (about 9 in girls) when it reaches a lower bound, it stays at that level for about a year or two and then during adolescence increases again considerably for about two years only to decline again and, asymptotically, approach zero. Through the use of 10 -year-old mean height data we are trying to avoid the too differing patterns of growth that may occur at previous and later ages, when growth is faster. The other reason is that height data is not always available at younger and older ages for as many countries as we analyze here.

${ }^{21}$ The 49 countries are -sorted by the average height of children- the Netherlands, West Germany, Switzerland, Norway, Sweden, Denmark, Hungary, Greece, Italy, Australia, New Zealand, United States, Canada, UK, Ireland, Belgium, Argentina, France, Turkey, Japan, Hong Kong, Costa Rica, Uruguay, Botswana, Brazil, Spain, Tanzania, Saudi Arabia, Fiji, Nigeria, Egypt, Sudan, Tunisia, Ghana, Chile, Zaire, Liberia, Gambia, Ethiopia, Kenya, South Korea, Philippines, Mexico, Bolivia, India, New Guinea, Malaysia, Guatemala, and Nepal. For six countries the average height is the linear average of the mean heights reported for rich and poor children.

${ }^{22}$ It is important to stress that the range of average heights to be explained is larger than the difference between children's height today and children's height 200 hundred years ago in western economies.
} 
Summary statistics for fertility are also shown in Table 1 . Notice that variability in net fertility is also very large, with a range of 5 surviving children per woman between the country with the largest level of net fertility (Kenya) and that with the lowest level (Hungary) ${ }^{23}$.

TABLE 1

SUMMARY STATISTICS

\begin{tabular}{|l|c|c|c|c|c|c|}
\hline & $\begin{array}{c}\text { Stature } \\
\text { (cm) }\end{array}$ & $\begin{array}{c}\text { Net } \\
\text { Fertility }\end{array}$ & $\begin{array}{c}\text { Per Capita GDP } \\
\text { (1985 prices) }\end{array}$ & $\begin{array}{c}\text { Literacy } \\
\text { Rate (\%) }\end{array}$ & $\begin{array}{c}\text { Primary } \\
\text { School (\%) }\end{array}$ & $\begin{array}{c}\text { Secondary } \\
\text { School (\%) }\end{array}$ \\
\hline Mean & 132.25 & 4.0 & 4,193 & 63 & 82 & 28 \\
Standard deviation & 6.85 & 1.6 & 3,745 & 35 & 36 & 23 \\
Maximum & 142.20 & 6.8 & 13,233 & 100 & 144 & 74 \\
Minimum & 105.00 & 1.8 & 257 & 7 & 5 & 1 \\
\hline
\end{tabular}

Source: Height data are from Eveleth and Tanner $(1976,1990)$; total fertility data are from the World Development Reports 1978 and 1994; mortality rates are from World Resources 1994-1995; income data from Penn World Table 5.6; literacy and schooling data are from the World Development Report 1978 and the Human Development Report 1994.

The logarithm of per capita GDP -in 1985 international prices-is our measure of income per capita. These values for income per capita are comparable across countries and over time. Summary statistics for GDP per capita are shown in Table 1. The range of income across economies is about 13,000 dollars, with the poorest economy being Ethiopia (1965) with an income per capita of 257 dollars, and the richest being the USA with an income per capita of 13,233 in 1980.

Two different measures of adult education are included in the estimation. Adult education is measured by adult literacy rates and by primary and secondary school enrollment. Statistics for adult literacy and school enrollment are shown in Table 1. The range in adult educational attainment across countries in the sample is also large.

${ }^{23}$ The range of values for net fertility in our sample is as large as the one observed between fertility levels today and 200 years ago in western economies. 


\subsection{Results}

\section{GDP, Fertility, and Children's Height}

The main regression results are shown in Table 2 . The estimated model for the log of children's height is shown in the first two columns, while the estimated model for the log of net fertility is shown in columns (3) and (4). The estimated relations have the expected shape.

The estimated relation between log fertility and $\log (\mathrm{GDP})$ yields an income elasticity of net fertility equal to 1.27-0.178 $\log (G D P)$; this means that the estimated relationship is positive as long as GDP per capita is lower than 1,254 dollars (at 1985 prices), and negative at larger levels of income ${ }^{24}$.

The estimated relation between log of average stature and $\log (\mathrm{GDP})$ implies an income elasticity of height equal to $-0.18+0.026 \log (G D P)$. Therefore the estimated relationship is negative for per capita GDP values lower than 1,015 dollars (1985 prices), but positive after that threshold level of income.

TABLE 2

\section{REGRESSIONS FOR FERTILITY ANDCHILDREN'S HEIGHT}

\begin{tabular}{|l|c|c|c|c|}
\hline & \multicolumn{2}{|c|}{ Log (Height) } & \multicolumn{2}{c|}{ Log (Fertility) } \\
\hline Regressors & $\mathbf{( 1 )}$ & $\mathbf{( 2 )}$ & $\mathbf{( 3 )}$ & $\mathbf{( 4 )}$ \\
\hline Log(GDP) & -0.18 & -0.13 & 1.27 & 1.58 \\
& $(0.075)$ & $(0.069)$ & $(0.4)$ & $(0.34)$ \\
\hline Log(GDP) squared & 0.013 & 0.0094 & -0.089 & -0.11 \\
& $(0.005)$ & $(0.0043)$ & $(0.026)$ & $(0.023)$ \\
\hline Literacy rate & & 0.0007 & & 0.0075 \\
& & $(0.0002)$ & & $(0.003)$ \\
\hline Primary school & 0.00063 & & -0.002 & \\
& $(0.00037)$ & & $(0.002)$ & \\
\hline Secondary school & 0.0001 & & -0.0076 & \\
& $(0.0003)$ & & $(0.0035)$ & \\
\hline Constant & 5.47 & 5.28 & -2.66 & -3.89 \\
& $(0.28)$ & $(0.27)$ & $(1.52)$ & $(1.28)$ \\
\hline No. observations & 49 & 49 & 49 & 49 \\
R-squared & 0.48 & 0.47 & 0.62 & 0.64 \\
\hline
\end{tabular}

Note: Standard errors in parenthesis.

${ }^{26}$ Income elasticity equals the coefficient of $\log (\mathrm{GDP})$ plus two times the coefficient of (Log(GDP) squared) times Log(GDP). 
Overall the fit of the model is good, and supports the predicted U-shaped relation between children's average height and GDP that is contemporaneous to an inverted U-shaped relation between fertility and income per capita. These findings are also consistent with the model's prediction that the level of income per capita at which fertility peaks is larger than the level of income per capita at which height reaches its lowest bound. Graph 4 shows how the estimated relations fit the data.

How do we interpret these results? According to the model in Section 2, the estimated negative relation between children's average height and per capita GDP for economies with an income lower than 1,015 dollars is driven by the positive relation between income per capita and net fertility estimated for that same range of income. Likewise, the positive relation between stature and income estimated at higher levels of income per capita is attributed to the joint phenomena of declining fertility and increasing adult consumption.

One should take the quadratic log-log specification as just an approximation to the nonlinear relation between height and income. One clear drawback of this specification is the implication that once the income threshold has been reached income elasticity of height increases with income per capita, albeit at a declining rate. This double log specification notwithstanding, the income elasticity of height found here is much smaller than that found in a previous study by Steckel (1983). He reports an elasticity of 0.27 while our estimated elasticity not only depends on $\log (\mathrm{GDP})$ but is smaller than his estimates for all possible values of income per capita.

Regarding the effect of adult education, we find that adult literacy rates are positive and significantly related to children's average stature, and negatively related to net fertility. In terms of school enrollment, average height is positively associated with primary school enrollment but not with secondary school enrollment, while net fertility is negatively associated with secondary school enrollment but not with primary school enrollment.

These results support the prediction of the model that income per capita growth does not have an immediate effect on the quality of life of children. Improvements in the quality of life of children are sizeable only when net fertility starts to decline and income per capita levels are large enough.

It is important to emphasize here that the model of Section 2 tells us that this pattern of development results from the utility maximizing behavior of families during the process of economic growth as they choose between bearing more children and improving their quality of life. 


\title{
GRAPH 4
}

\section{CHILDREN'S AVERAGE STATURE AND NET FERTILITY AGAINST GDP}

\author{
Children’s Average Stature Against GDP
}

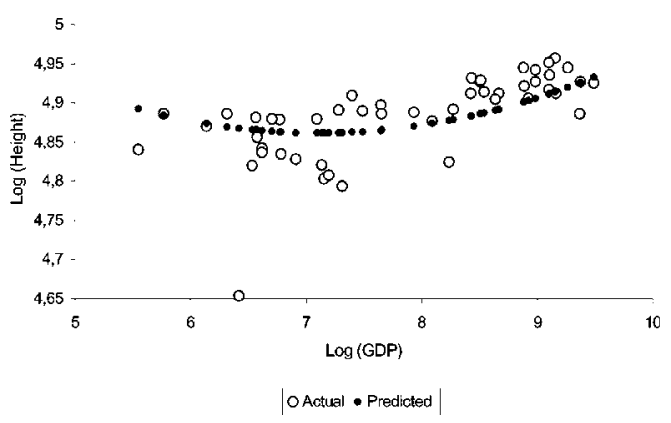

Net Fertility against GDP

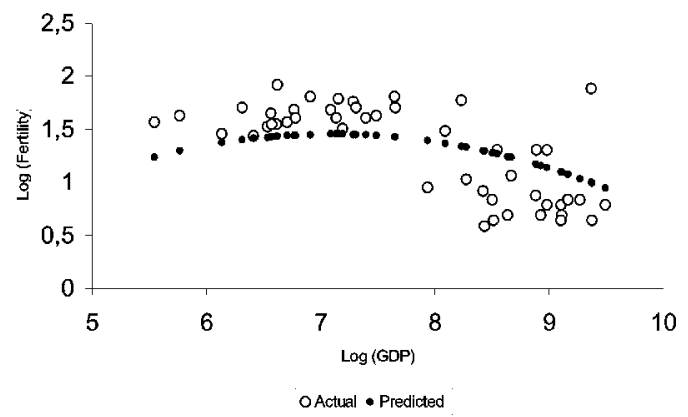

Income Inequality and Exogenous Changes in Stature

Steckel (1983 and 1995) argues that the variability in average heights is sensitive to income inequality, and that the relation between income per capita and average children's height is not correctly estimated unless we control for inequality in the estimation. The idea is that larger inequality, given income per capita, is associated with a larger percentage of children living in poorer conditions and thus with a lower average stature. 
To control for income inequality we include the Gini index in our regressions ${ }^{25}$. Barro (2000) shows that the Gini index is actually determined by income per capita and measures of human capital. Then, to estimate the model we have to resort to instrumental variable (IV) estimation ${ }^{26}$. The result of controlling for inequality is shown in Table 3, regression (1). The U-shaped relation between average stature and $\log (\mathrm{GDP})$ survives the inclusion of the Gini index, although the coefficients are only significant at a $10 \%$ level. The coefficient for the Gini index is negative, as expected, but statistically insignificant.

The possibility that a quality of life indicator may change over time holding income constant has been explored by Easterly (1999). He called these changes «exogenous» in the sense that they might represent endogenous global innovations which are a function of the global growth rate and independent of individual country income growth. Easterly finds that these exogenous changes explain a sizeable part of the change in several indicators of the quality of life. Given that the year of height measurement differs from one country to another in our sample -with a span of 25 years from the oldest to the most recent observation-, average heights might be affected by time.

To control for these exogenous changes we include a time trend variable which measures for each observation the number of years elapsed since 1960, the first year for which we have an observation in our sample.

Once we include time as an independent variable in the estimation of average stature, $\log (\mathrm{GDP})$ and adult education become endogenous themselves in the regression, and we have to estimate this specification using IV estimation. The instruments for $\log (G D P)$ and adult education are the predicted values of $\log (G D P)$ and adult education, respectively, that are obtained by regressing them on the time trend variable and other country characteristics.

The result of this estimation is shown in Table 3, regression (2). The estimated relation between children's average stature and GDP remains the same as before, and the estimated coefficient of time is statistically insignificant.

Summarizing, the estimated nonlinear relation between children's average stature and income per capita does not seem to be disturbed whenever we control for income inequality and year of height measurement.

\footnotetext{
${ }^{25}$ The values for the Gini index come from Deininger and Squire (1996). The criterion used to select the Gini values from the database was to choose the highest quality measure of the Gini index available for the year closest to that of birth of the children in the corresponding country.

${ }^{26}$ The instrument for the Gini index is its predicted value in the regression of the Gini index on Log(GDP), Log(GDP) squared, adult education, countries' cultural and other characteristics, and the time trend variable.
} 
TABLE 3

CONTROLLING FOR INEQUALITYANDEXOGENOUS CHANGES

\begin{tabular}{|l|c|c|}
\hline & \multicolumn{2}{|c|}{ Log (Height) } \\
\hline Regressors & $\mathbf{( 1 )}$ & $\mathbf{( 2 )}$ \\
\hline Log(GDP) & -0.125 & -0.20 \\
& $(0.07)$ & $(0.097)$ \\
\hline Log(GDP) squared & 0.009 & 0.015 \\
& $(0.0047)$ & $(0.007)$ \\
\hline Primary School & 0.0009 & 0.0001 \\
& $(0.0004)$ & $(0.0005)$ \\
\hline Secondary School & -0.0008 & $5,00 \mathrm{E}-06$ \\
& $(0.0006)$ & $(0.0012)$ \\
\hline Gini Index & -0.0025 & \\
& $(0.002)$ & \\
\hline Time & & $7,00 \mathrm{E}-06$ \\
& & $(0.001)$ \\
\hline Constant & 5.34 & 5.52 \\
& $(0.27)$ & $(0.32)$ \\
\hline No. Observations & 47 & 49 \\
R-squared & 0.48 & 0.39 \\
\hline
\end{tabular}

Note: Standard errors in parenthesis.

\section{DISCUSSION}

In the two previous sections a unified explanation is given for the evolution of children's height in Europe from the onset of the industrial revolution to the present days. Our model shows that the historical stages of decline, stagnation, and growth in heights are all part of a process associated with the industrial revolution and demographic transition. The puzzle of declining heights during periods of increasing income thus disappears once we introduce fertility into the picture.

It is important to stress here the economics behind our unified explanation. We assume that utility-maximizing households, who are constrained by income, time, 
and other resources, have to choose between the number of surviving children they have and the resources they allocate to each of them. For the representative household in a poor but growing economy higher net fertility is preferred to children's quality of life, and the opposite is true when income per capita is above a certain threshold level. This development leads to a deterioration of children's living conditions and health indicators during the initial stages of economic growth, and to fast improvements in children's living conditions and health indicators at later stages of economic growth.

The model is sufficiently stylized so that its assumptions can be specialized to the specific environment of interest to economic historians and still retain the main quantity-quality trade-off. For instance, consider the cost of children: the form we have assumed for this cost function could be easily reinterpreted to accommodate the historical patterns of child labor participation; uses of time by women; women labor participation; the gender wage gap, and government's labor legislation, etc., developments which might have affected the cost of children in the same way as capital accumulation does in the model.

The important point is that costs are involved and that they affect the quality and quantity of children. The fact that this quantity-quality trade-off is also the main building block of most successful theories of the demographic transition and the transition from Malthusian stagnation to sustained growth is another point in favor of our approach. Other explanations of the evolution of height changes which do not involve fertility considerations lack this symmetry and are less universal.

Since the industrial revolution and the demographic transition have proceeded at different pace across countries of the World, it is not surprising that the pattern analyzed in the model is also found in a contemporary cross-section of countries, as shown in Section 3.

An interesting exercise is to ask how well these cross-country estimates can account for the very long-run changes in children's stature in Europe. After all, the range in the values of average height, income, education, and fertility observed in our sample of contemporary economies approximately matches the range observed in the values of those variables over time, between the early nineteenth century and the second half of the twentieth century.

Let's consider the case of English heights. According to Tanner, Whitehouse and Takaishi (1966) the mean height of 13-year-old English boys born in 1952 was $153.4 \mathrm{~cm}$, while it was $137.3 \mathrm{~cm}$ for those born in 1820 -according to Floud, Wachter and Gregory (1990) - or even lower, $129.43 \mathrm{~cm}$ according to Komlos (1993a). How could our estimates be used to account for this observed long-run change in children's stature?

First note that our empirical model has been fitted to data on 10-year-old boys height. We thus need to change the estimated value of the constant from 5.47 to 5.55 to capture the $20 \mathrm{~cm}$ difference existent on average between 13- and 10-year-old 
boys in England around 1965. Given that income per capita was 6,987 (1990 GearyKhamis) dollars in England in 1952, and if we assume that primary school enrollment was around $92 \%$ at the time, then the estimates in Table 2, column (1), correctly predict that the stature of 13-year-old boys born in 1952 was $153.43 \mathrm{~cm}$.

We would then like to know what the predicted stature is when income per capita is 1,756 (1990 Geary-Khamis) dollars -the income per capita in England in 1820-, primary school enrollment is about 30\% -the enrollment prevailing in England in 1820 -, and we keep the constant term at $5.55^{27}$. It turns out that the predicted stature is $141.13 \mathrm{~cm}$. This value is still larger than the $137.3 \mathrm{~cm}$. reported by Floud, Wachter and Gregory (1990).

The reason why the model overestimates for 1820 might be that it is calibrated for all English boys in 1965, whereas the height data for 1820 is for the ultra-poor boys of London, and one would expect their height to be much lower than the average. Note that, according to Floud et al. (1990, p. 176), the heights of the upper class 13-year-olds was about $150 \mathrm{~cm}$. So the mean height was certainly above that of the poor boys. In addition, growth in height between age 10 and age 13 was much less in the nineteenth century than nowadays. Komlos (1986) shows that in early nineteenth century the incremental growth was closer to $12 \mathrm{~cm}^{28}$. Actually, the 3.8$\mathrm{cm}$-discrepancy in our exercise is fully explained if this difference was $12.9 \mathrm{~cm}^{29}$. We thus conclude that our cross-country sample estimates explain quite well the changes in height observed in the very long-run in England.

${ }^{27}$ The values for income per capita in 1990 Geary-Khamis dollars are taken from Maddison (1995). Crafts (1997) reports that the average number of years of schooling in the English population around 1820 was 2 years. Assuming that a percentage of the population enrolls in primary education and the rest does not enroll in any kind of educational program at all, and further assuming that completing primary education takes between 6 and 7 years, then average adult educational attainment in terms of primary school enrollment must have been around $30 \%$.

${ }^{28}$ This argument, which clearly explains why our model overestimates the height for 1820, was kindly provided to us by an anonymous referee.

${ }^{29}$ The same exercise can be carried out using literacy rate as the measure of adult educational attainment. In this case we change the estimated value of the constant from 5.28 to 5.38 to capture the $20 \mathrm{~cm}$ difference existent on average between 13 and 10 yearold boys in England around 1965. Using the income per capita in England in 1952, and assuming a literacy rate of $95 \%$ at the time, the estimates in Table 2, column (2), correctly predict that the stature of 13-year old boys born in 1952 was $153.3 \mathrm{~cm}$. The predicted stature for the income per capita in England in 1820, with the same constant term and the literacy rate prevailing in England in 1820 -54.5\% according to Crafts (1997) - is 144.25 $\mathrm{cm}$. This value is larger than the $137.3 \mathrm{~cm}$. reported by Floud, Wachter and Gregory (1990). The remaining $6.9 \mathrm{~cm}$ are explained if the difference in stature between 13 year-olds and 10 year-olds was $10.3 \mathrm{~cm}$ in 1820 . 


\section{REFERENCES}

Barro, R. J. (2000): «Inequality and Growth in a Panel of Countries». Journal of Economic Growth 5, pp. 5-32.

Barro, R. J., and Sala-I-Martin, X. (1995): Economic Growth. New York: McGraw-Hill.

Becker, G. S. (1965): «A Theory of the Allocation of Time». Economic Journal 75 (299), pp. 493-517.

Becker, G. S. (1976): «An Economic Analysis of Fertility», in The Economic Approach to Human Behavior. Chicago: The University of Chicago Press, pp. 171-194.

BeCKER, G. S., and BARro, R. J. (1988): «A Reformulation of the Economic Theory of Fertility». Quarterly Journal of Economics 103 (1), pp. 1-25.

Becker, G. S., Murphy, K. M. and Tamura, R. (1990): «Human Capital, Fertility and Economic Growth». Journal of Political Economy 98, pp. S12-S37.

Case, A., Lubotsky, D. and Paxson, C. (2001): «Economic Status and Health in Childhood: The Origins of the Gradient». Boston, MA: NBER Working Paper ${ }^{\circ}$. W8344.

Cigno, A. (1991): Economics of the Family. Oxford: Oxford University Press.

Coll, S., and Quiroga, G. (1994): «Height and the standard of living in $20^{\text {th }}$ century Spain: A preliminary report». Santander, Spain: Universidad de Cantabria. Departamento de Economía. Working paper $n^{\circ} 9405$.

Crafts, N. F. R. (1997): "Some dimensions of the 'quality of life' during the British industrial revolution». Economic History Review L (4), pp. 617-639.

Dasgupta, P. (1993): An Inquiry into Well-Being and Destitution. Oxford: Oxford University Press.

Deininger, K., and Squire, L. (1996): «A New Data Set Measuring Income Inequality». The World Bank Economic Review 10 (3), pp. 565-591.

EASTerLy, W. (1999): «Life During Growth». Journal of Economic Growth 4 (3), pp. 239276.

EcKstein, Z., Mira, P., and Wolpin, K. I. (1997): A Quantitative Analysis of Swedish Fertility Dynamics, 1751-1990. Madrid: CEMFI. Working Paper.

Eveleth, P. B., and Tanner, J. M. (1976): Worldwide Variation in Human Growth. Cambridge: Cambridge University Press.

— (1990): Worldwide Variation in Human Growth. Cambridge, UK: Cambridge University Press.

Floud, R., Wachter, K., and Gregory, A. (1990): Height, Health and History: Nutritional Status in the United Kingdom, 1750-1980. Cambridge: Cambridge University Press.

- (1993a): «Measuring Historical Heights - Short Cuts or the Long Way Round: a Reply to Komlos». Economic History Review 46 (1), pp. 145-154.

- (1993b): «Further Thoughts on the Nutritional Status of the British Population». Economic History Review 46 (2), pp. 367-368.

FogeL, R. W. (1994): «Economic Growth, Population Theory, and Physiology: The Bearing of Long-Term Processes on the Making of Economic Policy». American Economic Review 84 (3), pp. 369-395.

Frank, J. W., and Mustard, J. F. (1992): «The Determinants of Health from a Historical Perspective». Dredalus 121, pp. 1-19.

Frongillo, E. A., and Hanson, K. M. (1995): «Determinants of Variability Among Nations in Child Growth». Annals of Human Biology XXII (5), pp. 395-411. 
Galor, O., and Weil, D. N. (1996): «The Gender Gap, Fertility, and Growth». American Economic Review 86 (3), pp. 374-87

- (2000): «Population, Technology, and Growth: From Malthusian Stagnation to the Demographic Transition and Beyond». American Economic Review 90 (4), pp. 806828.

Galor, O., and Moav O. (2002): «Natural Selection and the Origin of Economic Growth». Quarterly Journal of Economics CXVII (4), pp. 1133- 1191.

HARRIS, B. (1994): «The Height of Schoolchildren in Britain, 1900-1950», in J. Komlos (ed.), Stature, Standard of Living and Economic Development: Essays in Anthropometric History. Chicago: University of Chicago Press, pp. 25-38.

Haveman, R., and Wolfe, B. (1995): «The Determinants of Children's Attainments: A Review of Methods and Findings». Journal of Economic Literature 33, pp. 1829-1878.

Komlos, J. (1986): «Patterns of Children's Growth in East-Central Europe in the Eighteenth Century». Annals of Human Biology 13, pp. 33-48.

- (1989): Nutrition and Economic Development in the Eighteenth-Century Habsburg Monarchy: An Anthropometric History. Princeton: Princeton University Press.

- (1993a): «The Secular Trend in the Biological Standard of Living in the United Kingdom, 1730-1860». Economic History Review 46 (1), pp. 115-144.

- (1993b): «Further Thoughts on the Nutritional Status of the British Population». Economic History Review 46 (2), pp. 363-366.

- (1996): "Anomalies in Economic History: Toward a Resolution of the 'Antebellum Puzzle'». The Journal of Economic History 56 (1), pp. 202-214.

- (1998): «Shrinking in a Growing Economy? The Mystery of Physical Stature during the Industrial Revolution». The Journal of Economic History 58 (3), pp. 779-802.

Komlos, J., and Coclanis, P. (1997): «On the Puzzling Cycle in the Biological Standard of Living: The Case of Antebellum Georgia». Explorations in Economic History 34, pp. 433-459.

LancAster, K. (1991): Modern Consumer Theory. New York: Columbia University Press.

LuCAS, R. E., Jr. (2002): Lectures on Economic Growth. Cambridge, MA: Harvard University Press.

Martínez Carrión, J. M. (1994): «Stature, Welfare, and Economic Growth in Nineteenth Century Spain: The Case of Murcia», in J. Komlos (Ed.), Stature, Standard of Living, and Economic Development: Essays in Anthropometric History. Chicago: University of Chicago Press, pp. 76-89.

MadDison, A. (1995): Monitoring the World Economy 1820-1992. Paris: OECD.

Mulligan, C., and Sala-I-Martin, X. (1991): A Note on the Time-Elimination Method for Solving Recursive Economic Models. Boston, MA: NBER Technical Working Paper ${ }^{\circ}$ 166.

Pritchett, L., and Summers, L. (1996): «Wealthier is Healthier». Journal of Human Resources 31 (4), pp. 841-868.

Quiroga, G. (2001): «Estatura, diferencias regionales y sociales y niveles de vida en España (1893-1954)». Revista de Historia Económica XIX, pp. 175-200.

SANDBERG, L. G., and STECKEL, R. H. (1988): «Overpopulation and Malnutrition Rediscovered: Hard Times in Nineteenth Century Sweden». Explorations in Economic History 25 (1), pp. 1-19. 
— (1997): «Heights and Economic History: The Swedish Case». Annals of Human Biology 14, pp. 101-110.

SchneIDER, R. (1996): «Historical Note on Height and Parental Consumption Decisions». Economic Letters 50, pp. 279-283.

Steckel, R. H. (1983): «Height and Per Capita Income». Historical Methods 16 (1), pp. 17.

- (1995): «Stature and the Standard of Living». Journal of Economic Literature 33 (4), pp. 1903-1940.

Strauss, J., and Thomas, D. (1998): «Health, Nutrition, and Economic Development». Journal of Economic Literature 36, pp.766-817.

Tanner, J. M., Whitehouse, R. H., and Takaishi, M. (1966): «Standards from Birth to Maturity for Height, Weight, Height Velocity, and Weight Velocity: British Children, 1965. Part II». Archives of Diseases in Childhood 41, pp. 613-633.

U. S. Department of Commerce (1989): Historical Statistics of the United States. Colonial Times to 1970. Washington, D.C.: Kraus International Publications for the U.S. Bureau of Census.

van Meerten, M. A. (1990) : «Développement économique et stature en France, XIX-XX siècles». Annales ESC 45, pp. 755-777.

WeIr, D. R. (1993): «Parental Consumption Decisions and Child Health During the Early French Fertility Decline, 1790-1914». The Journal of Economic History 53 (2), pp. 259-274.

Wrigley, E.A., and Schofield, R. S. (1989): The Population History of England, 1541-187. Cambridge: Cambridge University Press. 